\title{
WORKOUT DYNAMICS OF NATIONAL TEAM IN RHYTHMIC GYMNASTICS WOMEN'S ENSEMBLE
}

\author{
Daniela Velcheva \\ National Sports Academy "Vassil Levski", Sofia, Bulgaria
}

Summary: The excellent performance and the bronze medal won by the national team of rhythmic gymnastics, women's ensemble of the Republic of Bulgaria at the Olympic Games held in Rio de Janeiro in 2016, gave us the opportunity to look at and analyze the means and the methods, the steps and the algorithm to achieve this high sports result. Solving objectively the problems, related to the processes of control and management of sports training, is of crucial importance for the theoretical knowledge in this relatively young, but increasingly popular Olympic sport. How the load exercises have been done as quantitative-quality and time processes, what training and non-training impacts are being used, what is their combination, and by what methods are implemented, including how the competition activity was built. We offer to your attention a complete record and analysis of the realized and registered voluminous material in the training conditions of the competitors during the two macro-cycles of the Olympic year.

The processed data gave us information about the accumulated term and cumulative effect. Especially important and informative for us was to track the security performance in percentages of the competition program of the ensemble in the combination with five ribbons and with two hoops and six clubs and compare their values as the percentages from previous racing years. The comparative analysis of the difficulty of this program compared to the main competitors the teams of Russia and Spain is sufficiently informative about the complexity of the combinations and has a direct bearing on the sporting result.

Key words: Rhythmic gymnastics, general indicators of the load exercises, specific indicators of the load exercises, ribbon, hoop, club, security performance in percentages.

\section{Introduction:}

The high sport results in the modern rhythmic gymnastics is a function of the continuous improvement of the training process, the continuous increase in the amount of training work done, by increasing the amount of training indicators and improving the internal structure of the load exercises (Hadzhiev N. 1991). One of the main criteria for achieving high sport results is well-organized training and its proper planning and management (Dobreva T. 2007, Gateva M. 2008).

The complexity of the training of rhythmic gymnastics ensemble stems from the fact that methods and means with a common uniformity of influence are applied to the five gymnasts forming the group, but the final result is not always unique. This depends on the individual characteristics of the athlete. When we are analyzing the magnitude of the training effect and its relation to the load exercises, we must note the complexity of referring the general impact to the individual performance (Lisitskaya T. 1984).

The question as to what proportion the quantitative side of each parameter should be is particularly relevant in today's rhythmic gymnastics training (Krücek E., Wiener-Usmanova I., Terekin R. 2017). The technology for the use of training and non-training means is the most important because it reflects the main methodical direction of the training as a purposeful adaptation process and qualifies the different coaching schools. One of the most important ways for the formation of modern technologies is the specialization of the training (Bachvarov M. 2003).

\section{Aim and Objectives of the study:}

The main aim of this work is to trace the dynamics of the general and specific workloads (exercises) in the sports training of a women's ensemble in rhythmic gymnastics for a period of one year. The main tasks that we have set are:

$\checkmark$ Analysis of the quantitative values of the individual parameters of the training load - general and specific.

$\checkmark \quad$ Calculating the percentage of security of performance in the Olympic game program.

$\checkmark$ Comparative analysis of the difficulty of the composition compared to the main competitors.

\section{Methods:}

The methodological sequence of the study was conducted in several main directions during the two macrocycles of the competition year:

$>$ First macrocycle with five mezzo-cycles, from January to June ending with participation in the European Championship in Holon - Israel.

Second macrocycle with two mezzo-cy- 
cles, July and August, ending with Olympic Games held in Rio de Janeiro, Brazil.

- Pedagogical observation - Daily recording data of the work done in all types of training.

- A video analysis of the performance of the competition program during control exercises and competitions.

- Statistical processing of the obtained quantitative values by different parameters.

- Comparative analysis of the competitive forms of difficulty (number and type) of the combinations of main competitors Russia and Spain.

- Determination of the security percentage of the competition program of the two compositions, and for this purpose was calculated the number of non-error performed combinations compared to the total number of played combinations in the training and competition mode for the two periods.

\section{Results:}

The analysis of the common training means presented in Figure 1 shows a reduction in the number of training hours and keeping the maintenance of the number of training sessions and days in the competitive mezzo-cycles. The holiday days are evenly distributed over the months, their number being higher in the short recovering microcycles between the two major macrocycles and before the sports camp at Belmeken's high-altitude base.

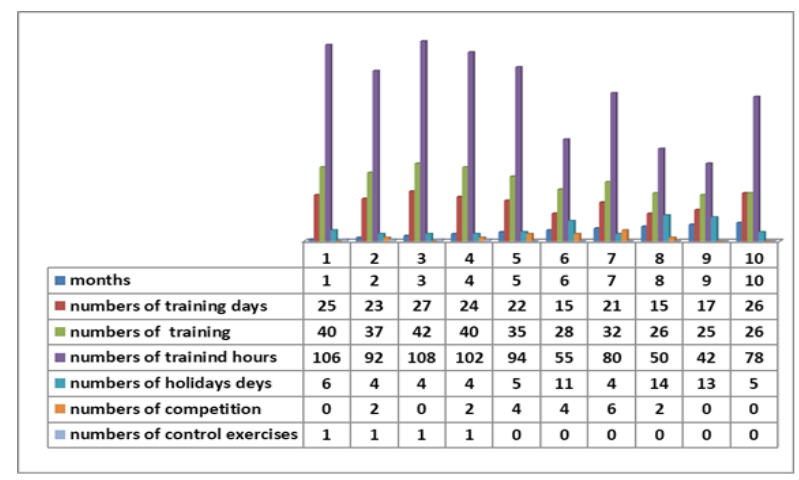

Fig. 1 General indicators of the load exercise

The Analysis of the common training data presented in Figure 2 shows an even distribution of the hours for general and specific physical abilities, with the prevalence of specialized training, except for the training regime implemented at the Belmeken camp. There is a large timeframe for choreographic training as an indispensable part in the daily training process.

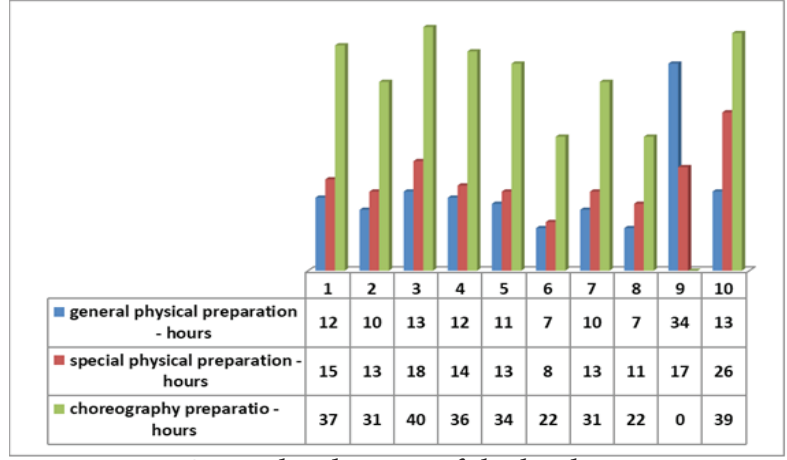

Fig. 2 General indicators of the load exercises

Figure 3 (five bands) and Figure 4 (two rings and six bats) show the specific training indicators. Performing a number of exercises with difficulty with body 1639 on ribbons and 1504 on hoops / clubs, the difference about the larger volume of ribbons is due to the specifics of the apparatus. The large overall length of the ribbon makes it more difficult to work without a mistake in performing the exercises. Performing a number of exchanges of 6394 ribbons and 7229 of hoops / clubs most of the exercises made in the second composition are due to the different technical approaches typical for the two different apparatus and their more complicated interaction. For the indicators, the number of quarters of the combination and the number of whole combination were performed, the number of exchanges performed on the two compositions were similar.

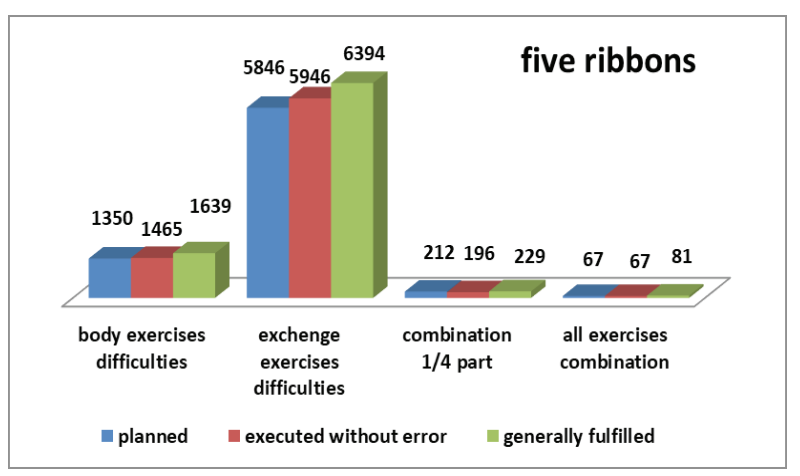

Fig.3 Specific load performance in practice - five ribbon

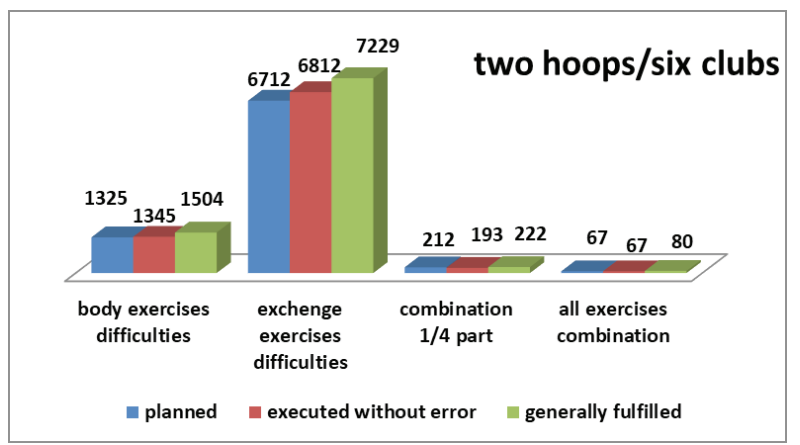

Fig.4 Specific load performance in practice - two hoops end six clubs 
The safety percentage and analysis results for the both combinations are shown in Figure 5 and Figure 6. It is of particular interest to us that this percentage for accomplished goals - 83\% ribbons and hoops / clubs $84 \%$ and the comparison of these data with the available ones since 2014. when the ensemble won the first place in the world championship in Izmir, then at a combination with ten clubs the security rate was $84 \%$ and the ribbons / balls $88 \%$

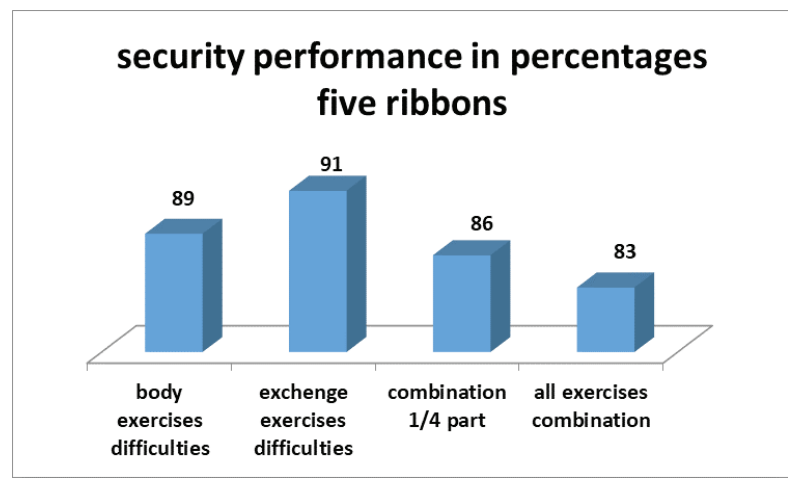

Fig.5 Security performance in percentages five ribbons

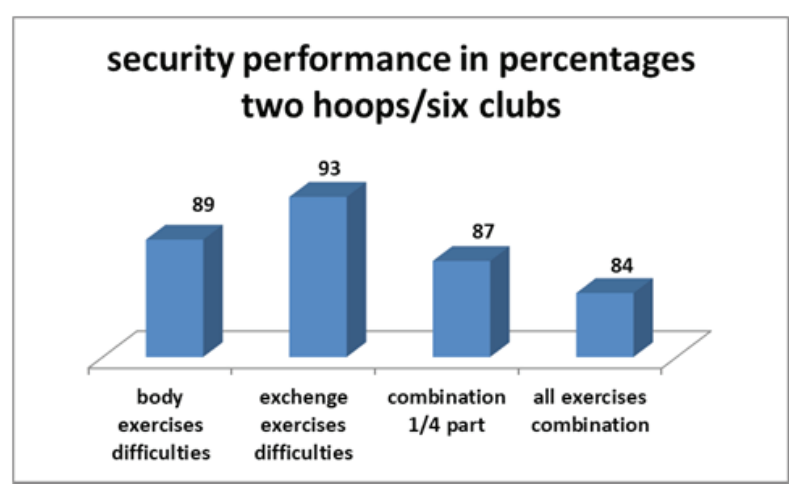

Fig.6 Security performance in percentages two hoops end six clubs

The comparative analysis of the difficulty of the combinations of the three ensembles led to the following results. The starting rating of the difficulty of the combinations of the teams of Russia, Spain and Bulgaria, who won the first three places in the Olympic games is 10.00 points. Differences are in the particular components of difficulty - Russia relies on the use of complex exercises with body -5 pcs. with average value of 0.6 pts, exchanges -4 pcs. and sophisticated collaboration with the instruments, Spain rely on high scores for performance and artistry of 9.2 pts. the highest one at the games, while the Bulgarian ensemble has a homogeneous distribution of difficulty with body -4 pcs. with an average of 0.5 pts, exchanges- 5 pcs, and risk work with the apparatus.

We can summarize the more general conclusions we have reached: $\checkmark$ The sport-competition year begins with a high number of training hours and a gradual reduction of this overall indicator before each competition in the two macrocycles, but the number of training sessions is maintained.

$\checkmark$ A saturated, constant and evenly distributed sports calendar is observed.

$\checkmark$ sports camping (adaptive) training days (4.08-19.08) in the second Macrocycle, held in Florianapolis - Brazil, have been successfully fulfilling their role for the good acclimatization of the team.

$\checkmark$ There is a high number of difficulties and exchanges in both compositions.

$\checkmark$ Characteristic of the specific training indicators is the approximately equal and high percentage of security of performance of the two combinations.

\section{Discussion:}

The problems with planning and implementing the optimal ratio of general and specific indicators applicable in the training process remain, because a common scheme or framework is impossible to implement without taking into account the individual qualities and functionalities of the contestants forming the ensemble. This is of great importance when replacing one or another player in the team or changing the whole team. The percentage of security is a very accurate indicator of the quality of the work done in the training process, and planning of complete goals without error will contribute to raising the level of training.

\section{References:}

Dobreva T. (2007), Podgotovka v sportnata gimnastika, $v$ pomosht na treniora, Bolid-Ins, Sofia

Bachvarov M. (2003), Sportologiy, Publishing House, Bolid - INS, Sofia

Krücek E., et al (2017), Hudojestvenna gimnastika istoria, sustoianie i perspectiva na razvitie, Sport $i$ Recreation 1

Lisitskaya T. (1984), Load group exercise on precompetitive stage www.cnopm.ru/gymnastics/training1984

Gateva M. (2008), Izsledvane na trenirovachnoto natovarvane $v$ hudojestvenata gimnastika $i$ usavarhsenstvane na metodikata na obuchenie, Sofia

Hadzhiev N. (1991) Optimizacia i upravlenie na sportnata podgotovka $v$ gimnastikata, NSA-PB, Sofia 